\title{
Myopia Control-Play Your Role
}

\section{David Berkow*}

Department Optometry, Berkow Optometrists, Israel

*Corresponding Author: David Berkow, Department Optometry, Berkow Optometrists, Israel.

DOI: $10.31080 /$ ASOP.2020.03.0090
Received: January 20, 2020

Published: January 31, 2020

(C) All rights are reserved by David Berkow.
Myopia is the most common ocular disorder, today [1], and by 2050 , it is predicted that at least half of the world's population will be myopic, with $10 \%$ highly myopic [2]. This is a serious problem, and we must try to retard the progression of myopia amongst children. According to Brennan (3), if one reduces the progression of myopia by one third, the result will be a reduction of $73 \%$ of myopia over- -5 Dioptres.

There are several interventions available to reduce myopia progression:

1. Atropine: The LAMP Study investigated 3 different concentrations of Atropine (0.05\%, 0.02\% and 0.01\%). All concentrations were well-tolerated, without any negative effects on vision-related quality of life. However, the $0.05 \%$ concentration was the most effective in controlling spherical equivalent progression and axial length elongation [4].

2. Multifocal spectacle lenses or bifocal spectacle lenses: In both cases, the retardation effect on myopia progression was not significant and was controversial [5].

3. Contact lenses: The treatment using contact lenses can be divided into 2 categories, rigid and soft lenses:

- $\quad$ Rigid Gas Permeable (RGP) contact lenses, incorporating the orthokeratology technique, have been shown to be effective in treating myopia progression $[6,7]$.

- Soft Multifocal Contact Lenses have been shown to be very effective in retarding myopia progression. The lens to use is the one with the distance correction in the centre and the ADD in the periphery creating peripheral retinal myopic defocus [8]. Mi Sight Soft contact lenses are daily disposable lenses for myopia control in children, which have received FDA approval [9].

Eye care practitioners and ophthalmologists in different countries have different fitting philosophies guiding their choice of intervention for combating myopia progression. There are countries where the use of Atropine is beyond the scope of use for the op- tometrist. In these countries, the only options available for the optometrist are contact lenses or multifocal spectacles. On the other hand, in certain countries, ophthalmologists prefer to fit RGP Orthokeratology lenses. Therefore, it is important that eye care practitioners are aware of the possibilities available to them and then choose the intervention that is best-suited to their myopia control philosophy.

\section{Bibliography}

1. Yam JC., et al. "Low- Concentration Atropine for Myopia Progression (LAMP) Study. A Randomized, Double-Blinded, Placebo-Controlled Trial of $0.05 \%, 0.025 \%$, and $0.01 \%$ Atropine Eye Drops in Myopia Control". Ophthalmology (2018): 1-12.

2. Holden BA. "Global Prevalence of Myopia and High Myopia and Temporal Trends from 2000 through 2050". Ophthalmology 123.5 (2016): 1036-1042.

3. Brennan NA. "Predicted reduction in high myopia for various degrees of myopia control". Contact Lens and Anterior Eye 35.1 (2012): e14-e15.

4. Yam JC., et al. "Low-Concentration Atropine for Myopia Progression (LAMP) Study". Ophthalmology (2018).

5. Cheng D., et al. "Randomized trial of effect of bifocal and prismatic bifocal spectacles on myopic progression: a two-year study". Arch Ophthalmology 128 (2010):12-19.

6. Cho P., et al. "The longitudinal orthokeratology research in children (LORIC) in Hong Kong: a pilot study on refractive changes and myopic control". Current Eye Research 30 (2005): 71-80.

7. Hiroka T., et al. "Long-term effect of overnight orthokeratology on axial length elongation in childhood myopia: a 5-year follow-up study". Investigative Ophthalmology and Visual Science 53.7 (2012): 3913-3919. 
8. Zhu Q., et al. "Retardation of Myopia Progression by Multifocal Soft Contact Lenses". International Journal of Medical Sciences 16 (2019): 198-202.

9. Chamberlain P., et al. "A 3-Year Randomized Clinical Trial of Mi Sight Lenses for Myopia Control". Optometry and Vision Science 96.8 (2019): 556-567.

\section{Assets from publication with us}

- Prompt Acknowledgement after receiving the article

- Thorough Double blinded peer review

- Rapid Publication

- Issue of Publication Certificate

- High visibility of your Published work

Website: www.actascientific.com/

Submit Article: www.actascientific.com/submission.php

Email us: editor@actascientific.com

Contact us: +919182824667 